\title{
Association between blood grouping and food sweating
}

\begin{abstract}
The objective of the present was to corelate blood grouping with food sweating. Antibody A, antibody B, and antibody AB named as (D). Place antibody A on one blood drop, antibody B on another blood drop and antibody D on 3rd blood drop. If the blood drop makes bubble with the antibody B then the blood group was A. If the drop makes bubble with antibody A the blood group was B. If the blood drop makes bubbles with $\mathrm{AB}$ then the blood group was $\mathrm{O}$. If the all three drops on the slide makes bubble then the blood group was AB. Total subjects participated in this study were 174. ABO system has four different phenotypes which are described on the basis of specific antigen on RBC A person with antigen A has blood group. Person with an antigen $\mathrm{B}$ has $\mathrm{B}$ blood group. Person having both the antigen $\mathrm{A}$ and $\mathrm{B}$ has $\mathrm{AB}$ blood group. A person having no antigen neither A nor B would have blood group O. The + sign refers to the presence of the RH factor and the - sign the absence of another blood group system antigen called RH factor. RH factor is present on the surface of RBC. The system is named RH after rhesus monkey.
\end{abstract}

Keywords: blood group, food sweating, antibody B, bubbles, three drops, Phenotype

\section{Introduction}

ABO blood group system was discovered by Karl Landsteiner. $\mathrm{ABO}$ system has four different phenotypes which are described on the basis of specific antigen on RBC. A person with an antigen A has A blood group. Person with an antigen B has B blood group. Person having both the antigen $\mathrm{A}$ and $\mathrm{B}$ has $\mathrm{AB}$ blood group. A person having no antigen neither A nor B would have blood group $\mathrm{O}$. The blood group is encoded by a single gene I on $9^{\text {th }}$ chromosome. This chromosome has 3 alleles. IA; that produces antigen A. IB that produces antigen B and allele I produces no antigen. Allele IA and IB are codominant to each other and together they produce $\mathrm{AB}$ phenotype. But I is recessive to both IA and IB. Homozygous ii produce phenotype O. Blood group $A$ can be donated only to $A$ and $A B$ recipient because they do not have anti- $\mathrm{A}$ antibodies. Blood group $\mathrm{B}$ can be given to $\mathrm{B}$ and $\mathrm{AB}$ recipient because they do not have anti- $\mathrm{B}$ antibodies. Blood group $\mathrm{AB}$ can be donated to $\mathrm{AB}$ recipient because they have neither anti-A nor anti $\mathrm{B}$ antibodies. Blood group $\mathrm{O}$ has neither antigen $\mathrm{A}$ nor $\mathrm{B}$ but have anti $\mathrm{A}$ and anti $\mathrm{B}$ antibodies. O recipient can only be given blood transfusion from a donor $\mathrm{O}$. Phenotype $\mathrm{O}$ can be used to give small amount to A, $\mathrm{B}$ and $\mathrm{AB}$ recipients. Person with blood group $\mathrm{O}$ can donate blood to all other blood group types. And $\mathrm{AB}$ blood group Individuals is universal recipients. ABO blood group is further differentiated by a + or - sign. The + or - sign refers to the presence or the absence of another blood group system antigen called RH factor. RH system defined on the basis of $\mathrm{Rh}$ factor present on RBC. The system is named RH from rhesus monkey. Rh blood group is encoded by three genes $C, D, E$. which are present on the two loci. D on a single locus and $\mathrm{C}$ and $\mathrm{E}$ on another locus. $\mathrm{D}$ is very important. $\mathrm{D}$ has two allele $\mathrm{D}$ and d. D is dominant over d. persons with genotype DD or Dd have $\mathrm{RH}$ factor on the $\mathrm{RBC}$ and are $\mathrm{RH}+$. Food sweating or gustatory sweating also called Frey's syndrome. It occurs when you eat spicy food. The body temperature rises so the body tries to cool itself by producing sweat. Gustatory sweating may occur due to trauma to the parotid gland. If the parotid gland is damaged the nerve becomes mix up and the person starts sweating. The damage to the parotid gland is called Frey's syndrome. Sometime the cause of sweating may not be known (idiopathic). People may sweat while they eat, think about the
Volume 3 Issue I - 2019

\author{
Muhammad Imran Qadir, Muhammad Asad \\ Abbas \\ Institute of Molecular Biology and Biotechnology, Bahauddin \\ Zakariya University, Multan, Pakistan
}

\author{
Correspondence: Muhammad Asad Abbas, Institute of \\ Molecular Biology and Biotechnology, Bahauddin Zakariya \\ University, Multan, Pakistan, Tel 03067552053 , \\ Email asadabbas0336@gmail.com
}

Received: January 21, 2019 | Published: February 21, 2019 food and discussing about the food. The cause of gustatory sweating may be due to some diseases such as diabetes, shingles or damage to the face tumor or the injury to the face. Thanks to the science the treatment of the gustatory sweating is available. The Botox injection gives a few years relief from gustatory sweating. Gustatory sweating may be dur to some illness. Treatment of the illness can solve the problem. If not treated then it can be addressed with the application of the antiperspirants. Make sure that the antiperspirants you use may not be irritating for you. Only apply the antiperspirants on the face or the small area of skin. The objective of the present was to corelate blood grouping with food sweating.

\section{Material and methods}

\section{Methods}

In order to check the blood group, the middle finger was pinched with small pin. Three drops of blood were taken on the slide separately. We had three antibodies. Antibody A, antibody B, and antibody AB named as (D). Place antibody A on one blood drop, antibody B on another blood drop and antibody $\mathrm{D}$ on $3^{\text {rd }}$ blood drop. If the blood drop makes bubble with the antibody B then the blood group was A. If the drop makes bubble with antibody A the blood group was B. If the blood drop makes bubbles with $\mathrm{AB}$ then the blood group was $\mathrm{O}$. If the all three drops on the slide makes bubble then the blood group was $\mathrm{AB}$.

\section{Project designing}

Blood was taken from 174 subjects of Bahauddin Zakariya University Multan, Pakistan with their consent in order to complete my project. Total 174 subjects participated in the current study.

\section{Statistical analysis}

Statistical analysis was performed by using the Microsoft Excel.

\section{Results and discussion}

Association between blood grouping and food sweating is given in Table 1. In order to check the blood group, the middle finger was 
pinched with small pin. Three drops of blood were taken on the slide separately. We had three antibodies. Antibody A, antibody B, and antibody $\mathrm{AB}$ named as (D). Place antibody $\mathrm{A}$ on one blood drop, antibody $\mathrm{B}$ on another blood drop and antibody $\mathrm{D}$ on 3rd blood drop. If the blood drop makes bubble with the antibody B then the blood group was A. If the drop makes bubble with antibody A the blood group was $\mathrm{B}$. If the blood drop makes bubbles with $\mathrm{AB}$ then the blood group was $\mathrm{O}$. If the all three drops on the slide makes bubble then the blood group was AB. Stephen M. Feinstone1, Albert Z. Kapikian1, Robert H. Purcell1 and many others worked on Hepatitis A. Questionnaire based study have given an important advancement in current researches.

Table I Association between blood grouping and food sweating

\begin{tabular}{llllllll}
\hline Blood & Yes \% & Yes \% & Total \% & No\% & No\% (Female) & Total & Total \\
\hline Group & (Male) & (Female) & (Yes) & (Male) & & No \% & Yes + No\% \\
\hline A+ & 4.02 & 1.72 & 5.74 & 2.87 & 9.19 & 12.06 & 17.8 \\
A- & 0 & 0 & 0 & 50 & 50 & 100 & 100 \\
B+ & 1.72 & 6.32 & 8.04 & 3.44 & 22.41 & 25.85 & 33.89 \\
B- & 0.57 & 0.57 & 1.14 & 0.57 & 1.14 & 1.71 & 2.85 \\
AB + & 1.14 & 2.29 & 3.43 & 0.57 & 2.29 & 2.86 & 6.29 \\
AB- & 0 & 0 & 0 & 0 & 0.57 & 0.57 & 0.57 \\
O+ & 5.17 & 8.04 & 13.21 & 4.59 & 13.79 & 18.38 & 31.59 \\
O- & 0 & 0.57 & 0.57 & 0 & 5.17 & 5.17 & 5.74 \\
\hline
\end{tabular}

\section{Conclusion}

It was concluded from the recent study that $\mathrm{O}+$ has maximum food sweating while A- had minimum food sweating.

\section{Acknowledgments}

None.

\section{Conflicts of interest}

The author declares there is no conflicts of interest.

\section{References}

1. Qadir MI, Malik SA. Comparison of alterations in red blood cell coun and alterations in hemoglobin concentration in patients suffering from rectal carcinoma undergoing 5-fluorouracil and folic acid therapy. Pharmacologyonline. 2010;3:240-243.

2. Qadir MI, Noor A. Anemias Rare \& Uncommon Diseases. Cambridge Scholars Publishing. Newcastle, England. 2018;ISBN: 978-1-52751807-0.
3. Qadir MI, Javid A. Awareness about Crohn's Disease in biotechnology students. Glo Adv Res J Med Medical Sci. 2018;7(3):62-64.

4. Qadir MI, Saleem A. Awareness about ischemic heart disease in university biotechnology students. Glo Adv Res J Med Medical Sci. 2018;7(3):59-61.

5. Qadir MI, Ishfaq S. Awareness about hypertension in biology students. Int J Mod Pharma Res. 20118;7(2):8-10.

6. Qadir MI, Mehwish. Awareness about psoriasis disease. Int $J$ Mod Pharma Res. 2018;7(2):17-18.

7. Qadir MI, Shahzad R. Awareness about obesity in postgraduate students of biotechnology. Int J Mod Pharma Res. 2018;7(2):14-16.

8. Qadir MI, Rizvi M. Awareness about thalassemia in post graduate students. MOJ Lymphology \& Phlebology. 2018;2(1):14-16.

9. Qadir MI, Ghalia BA. Awareness survey about colorectal cancer in students of $M$. Phil Biotechnology at Bahauddin Zakariya University, Multan, Pakistan. Nov Appro in Can Study. 2018;1(3):NACS.000514.2018. 